\title{
Monoclonal Antibody ASP1948
}

National Cancer Institute

\section{Source}

National Cancer Institute. Monoclonal Antibody ASP1948. NCI Thesaurus. Code C156402.

A monoclonal antibody targeting a not yet disclosed immunomodulatory receptor, with potential antineoplastic activities. Upon intravenous administration, monoclonal antibody ASP1948 binds to its not yet disclosed target, which may stimulate an immune-mediated response against tumor cells. 